\title{
Effect of sugar reduction on flavour release and sensory perception in an orange juice soft drink model
}

Article

Accepted Version

Creative Commons: Attribution-Noncommercial-No Derivative Works 4.0

Tsitlakidou, P., Van Loey, A., Methven, L. and Elmore, S. (2019) Effect of sugar reduction on flavour release and sensory perception in an orange juice soft drink model. Food Chemistry, 284. pp. 125-132. ISSN 0308-8146 doi:

https://doi.org/10.1016/j.foodchem.2019.01.070 Available at https://centaur.reading.ac.uk/82059/

It is advisable to refer to the publisher's version if you intend to cite from the work. See Guidance on citing.

To link to this article DOI: http://dx.doi.org/10.1016/j.foodchem.2019.01.070

Publisher: Elsevier

All outputs in CentAUR are protected by Intellectual Property Rights law, including copyright law. Copyright and IPR is retained by the creators or other copyright holders. Terms and conditions for use of this material are defined in the End User Agreement.

www.reading.ac.uk/centaur 
Central Archive at the University of Reading

Reading's research outputs online 
1 Effect of sugar reduction on flavour release and sensory perception in

2

3

4 5

6

7

8

9 E-mail addresses:

10

11

12

13

14

15

16

17

18

19

20

21

22

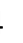

16

7

19

an orange juice soft drink model

Petroula Tsitlakidou ${ }^{1}$, Ann Van Loey ${ }^{2}$, Lisa Methven ${ }^{1}$, J. Stephen Elmore ${ }^{1^{*}}$

${ }^{1}$ Department of Food and Nutritional Sciences, University of Reading, Whiteknights, Reading RG6 6AP, UK

${ }^{2}$ Laboratory of Food Technology (member of Leuven Food Science and Nutrition Research Center, LFoRCe), Department of Microbial and Molecular Systems (M²S), KU Leuven, Kasteelpark Arenberg 22 box 2457, 3001 Heverlee, Belgium

Ms Petra Tsitlakidou: petratsitlak@hotmail.com

Prof. Ann Van Loey: Ann.VanLoey@kuleuven.be

Dr Lisa Methven; 1.methven@reading.ac.uk

Dr Stephen Elmore j.s.elmore@,reading.ac.uk (*corresponding author; tel.: +118-3787455) 
24 To examine the effect of sugar reduction on the sensory perception of sweetened beverages,

25 an orange juice soft drink model flavoured with seven characteristic compounds (hexanal, 26 decanal, linalool, ethyl butanoate, $\alpha$-pinene, $\beta$-myrcene and (Z)-3-hexen-1-ol) was developed.

27 Five samples were prepared with relevant sugar contents (5.2, 8.2, 9.7, 11.2 and $14.2{ }^{\circ}$ Brix).

28 Using retronasal quantitative descriptive analysis (QDA), nine attributes were found to differ significantly $(p<0.05)$ with sugar content. When the samples were evaluated orthonasally, only the attribute "overripe orange" significantly decreased $(p<0.05)$ with reduction of sugar content. Headspace solid-phase microextraction with gas chromatography-mass spectrometry showed that as sugar concentration decreased, the headspace concentration of six of the volatile compounds decreased, whilst ethyl butanoate remained constant. Principal component analysis revealed that the total release of the flavour compounds was highly correlated with the perceived intensity of the orthonasal attribute "overripe orange".

36 Keywords: Orange flavour; sugar reduction; salting-out; sensory analysis; direct gas

37 chromatography-olfactometry; headspace solid phase microextraction with gas chromatography-mass spectrometry; principal component analysis 


\section{Introduction}

The interest in developing "light" or "diet" beverages is rising, driven largely by the market potential for beverages that can maintain or promote the well-being of consumers. Beverage manufacturers have shown strong interest in addressing the challenge of sugar reduction in soft drinks, whilst maintaining the organoleptic characteristics, often using high intensity sweeteners to replace sugars. Yet little is known about the interactions between sugar and flavour in soft drinks and subsequent effects on sensory quality. To date, it has been suggested that an increase in release of specific flavour compounds with increasing sucrose concentration (from 20 to $60 \% w / w$ ) is possibly due to a "salting-out" effect (Hansson, Andersson, \& Leufven, 2001). Nahon and co-workers (Nahon, Roozen, \& de Graaf, 1998) investigated the release of an orange aroma in various mixtures of sucrose and sodium cyclamate. It was shown that there was a significant association between the retention time of a volatile compound on a gas chromatography column and its release behaviour. Specifically, the release rates of volatile compounds with short retention times intensified by increasing sucrose content from 0 to $60 \%(w / v)$ whilst flavour compounds with higher retention times were negatively influenced, if at all, by modifying sucrose concentration. Similar results were obtained by Rabe and her co-workers (Rabe, Krings, \& Berger, 2003), who revealed that various flavour compounds showed an increased release with increasing sugar content ranging from 0 to $500 \mathrm{~g} / \mathrm{L}$. Hence, it can be deduced from the aforementioned studies that the release rate of the volatiles is selectively influenced by the sucrose content, resulting in a significant shift of the flavour profile. However, when lower levels of sugars (glucose $0-150 \mathrm{~g} / \mathrm{L}$ and fructose $0-64 \mathrm{~g} / \mathrm{L}$ ) were applied in a model citrus-flavoured beverage, it was suggested that flavour enhancement was not fully explained by physicochemical interactions within the beverage matrix (Hewson, Hollowood, Chandra, \& Hort, 2008). Further investigation is required to clarify the effect on sensory perception of the 
sugar content in these soft drink model systems (sugar level at approximately $10 \% \mathrm{w} / \mathrm{v}$ ), since a number of studies have shown conflicting results.

Solid-phase microextraction (SPME) is a widely applied technique for volatile analysis in food/flavour chemistry, since it is a rapid, solvent-free and simple adsorption method for the isolation of headspace flavour compounds (Zhang \& Pawliszyn, 1993). To date, many studies have conducted flavour analysis of different citrus species/varieties (González-Mas, Rambla, Alamar, Gutiérrez, \& Granell, 2011), of fresh (Moshonas \& Shaw, 1994) or excessively heated orange juice (Bazemore, Goodner, \& Rouseff, 1999) and the presence of pulp in orange juice (Rega, Fournier, Nicklaus, \& Guichard, 2004), using headspace SPME followed by gas chromatography-mass spectrometry (HS-SPME/GC-MS).

The optimisation of SPME sampling and gas chromatographic conditions for both qualitative and quantitative analyses of volatile compounds in the headspace of orange juice has been investigated in the past (Jia, Zhang, \& Min, 1998). Several different types of fibres have been used in citrus studies, with the divinylbenzene/Carboxen ${ }^{\mathrm{TM}} /$ polydimethylsiloxane (DVB/CAR/PDMS) fibre predominantly used, due to its ability to extract from the orange juice matrix a large number of flavour compounds with different polarities (Berlinet, Guichard, Fournier, \& Ducruet, 2007; González-Mas et al., 2011; Rega, Fournier, \& Guichard, 2003).

The number and nature of the extracted volatile compounds are strongly dependent on the food type and matrix, as well as the sampling time of the fibre, heating temperature and time (Yang \& Peppard, 1994). In this sense, it has been suggested that a short time of sampling is preferable, to better represent the original headspace of samples (Rega et al., 2003; Roberts, Pollien, \& Milo, 2000). Rega and co-workers (2003) developed an instrumental method to evaluate odours from headspace extracts, in order to improve SPME performance, which they termed direct gas chromatography-olfactometry (D-GC-O). In this method, headspace 
extracts are injected into a deactivated fused silica capillary, which is attached to a GCsniffing port. Trained assessors sniff the extract coming out from the GC-sniffing port and rate the similarity of the headspace extract to the original headspace of the sample. By this method, various sampling conditions are validated, including type of fibre, extraction time, heating time and temperature (Berlinetet al., 2007; Rega et al., 2003).

A plethora of volatile compounds and key odorants in orange juice has been identified and their odour and flavour thresholds have been quantified (Plotto, Margaría, Goodner, \& Baldwin, 2008; Plotto, Margaría, Goodner, Goodrich, \& Baldwin, 2004). There is no single volatile in orange juice that can be considered as a character impact compound. Instead, the perception of orange flavour is a result of a group of aroma-active compounds present in low concentrations. In the current study, an orange flavour mixture was used, consisting of decanal, hexanal, (Z)-3-hexen-1-ol, ethyl butanoate, linalool, $\beta$-myrcene and $\alpha$-pinene, most of which have been found at higher concentration levels in processed orange juices than freshly-squeezed ones and are characterised as some of the key odorants in orange juice flavour (Moshonas \& Shaw, 1994). Decanal and hexanal are straight-chain aldehydes present at low concentration in processed juice and considered as an important contributor to the green, grassy note of orange juice flavour. Similarly, (Z)-3-hexen-1-ol contributes to the green/woody top notes of freshly squeezed orange juice. Ethyl butanoate is the single most important ester and most intense odorant in orange juice, imparting a fruity odour quality. Linalool is a terpene alcohol which contributes floral, sweet and fruity aromas. $\beta$-Myrcene and $\alpha$-pinene are the most abundant terpenes after limonene, and their levels depend on the peel oil content of the processed juice. These compounds are considered to possess a low odour-active intensity, with $\beta$-myrcene imparting a mossy odour note and $\alpha$-pinene a pinetree, resin odour quality (Perez-Cacho \& Rouseff, 2008). 
The objective of the current study was to examine how sugar reduction affects the release

of seven different flavour compounds (of known hydro-phobicity/philicity) and sensory perception in an orange juice soft drink model. Initially, a sensorial approach was implemented, conducting two independent quantitative descriptive analyses, one orthonasal and one retronasal, in order to investigate how sugar reduction can influence the sensory perception of orange juice soft drink samples. Then, $\mathrm{D}-\mathrm{GC}-\mathrm{O}$ was applied to determine the optimum experimental conditions to obtain the most representative SPME extract. Subsequently, samples were subjected to HS-SPME/GC-MS to examine whether the flavour release of the volatile compounds was influenced by sugar content modification, and to relate this to change in orthonasal perception.

\section{Materials and Methods}

\subsection{Materials and sample preparation}

The soft drink model system consisted of $7 \%(w / w)$ deodorised orange juice concentrate of $65^{\circ}$ Brix, a non-commercial orange flavour mixture, $0.25 \%(w / v)$ citric acid, and sucrose at five different concentrations. Givaudan Ltd (Milton Keynes, UK) provided the flavour mixture, which contained 7 compounds with known concentrations and different solubility properties, all dissolved in triacetin. Hexanal, decanal and linalool were present at $5 \mathrm{~g} / \mathrm{L}$. Ethyl butanoate was present at $50 \mathrm{~g} / \mathrm{L}, \alpha$-pinene at $37.5 \mathrm{~g} / \mathrm{L}, \beta$-myrcene at $12.5 \mathrm{~g} / \mathrm{L}$ and $(Z)-3$ hexen-1-ol at $20 \mathrm{~g} / \mathrm{L}$. The flavour mixture was dosed at $300 \mathrm{mg} / \mathrm{L}$ in all samples; thus, it was calculated that the dosage would deliver $1.5 \mathrm{mg} / \mathrm{L}$ for each of the compounds hexanal, decanal and linalool, $15 \mathrm{mg} / \mathrm{L}$ of ethyl butanoate, $11.25 \mathrm{mg} / \mathrm{L}$ of $\alpha$-pinene, $3.75 \mathrm{mg} / \mathrm{L} \beta$ myrcene and $6 \mathrm{mg} / \mathrm{L}$ of $(Z)-3$-hexen-1-ol in the soft drink model (Supplementary Table S1).

Five sucrose concentrations were chosen $(2.0,5.0,6.6,8.2$ and $11.5 \% w / v)$ resulting in samples of 5.2, 8.2, 9.7, 11.2 and $14.2^{\circ}$ Brix (the total sugar levels), determined by a hand- 
held refractometer- All sample preparation, pasteurisation, aseptic bottling and measurement of refractive index and acidity were performed by a commercial soft drinks manufacturer. Subsequently, bottles of juice were shipped and stored at $4{ }^{\circ} \mathrm{C}$ at the Department of Food and Nutritional Sciences, University of Reading, UK, until they were used for sensory and volatile compound analysis.

\subsection{Sensory analysis by quantitative descriptive profiling}

Samples of juice $(25 \mathrm{~mL})$ were poured into tulip-shaped whisky glasses (200 mL volume; Glencairn, East Kilbride, UK) and covered with a Petri dish for sensory evaluation. Samples were coded with 3-digit random codes and prepared 2 hours prior to tasting, to allow headspace equilibrium and ambient temperature to be reached.

A sensory panel $(n=8, n=9)$ based at the Sensory Science Centre (Department of Food and Nutritional Sciences, University of Reading) participated in two independent qualitative descriptive analysis (QDA) tests, one orthonasal and one retronasal assessment. The assessors were screened and trained, with a minimum of 6 months experience in sensory evaluation of flavour. An experienced sensory panel was preferred, to dissociate possible interactions from odour and taste modalities (Hewson, Hollowood, Chandra, \& Hort, 2008).

The orthonasal assessment preceded the retronasal assessment. At the beginning of each type of assessment, the panellists were asked to generate as many sensory terms as possible to describe the characteristics of all samples. Subsequently, the panel leader initiated a discussion to develop a consensus vocabulary, in which flavour characteristics of all samples were described and defined. There followed four training sessions on separate days, where various references were chosen to standardise the definitions of descriptors (Supplementary Table S2). Next, panellists individually rated samples in duplicate on two separate days, in individual booths under artificial daylight and at a room temperature of $23{ }^{\circ} \mathrm{C}$. Samples were presented monadically and in a balanced order. The intensity of each attribute was rated using 
unstructured line scales (scaled 0-100), with anchors predetermined by the consensus panel; data were captured using Compusense 5 software (Compusense, West Guelph, ON, Canada).

\subsection{Measuring representativeness of extraction by $H S-S P M E / D-G C-O$}

The D-GC-O method was performed to determine the SPME extract most representative of orange juice aroma. The trained panel $(n=7)$, who had previously undertaken the sensory profiling of the two sets and hence were familiar with the samples and the descriptors, participated in the $\mathrm{D}-\mathrm{GC}-\mathrm{O}$ analysis. A similarity test was carried out in duplicate on five SPME extracts obtained using different extraction conditions from the headspace of reference sample $11.2^{\circ}$ Brix. Sample $11.2^{\circ}$ Brix was chosen since it was the sample most assessed during QDA training of the panellists, thus it was the most familiar to them. The five different sets of experimental conditions for aroma extraction are shown in Error! Reference

source not found. Initially longer fibre exposure periods were tested (15-30 minutes).

However, this led to fibre overload and poor chromatography (data not shown) All samples were subjected to agitation during equilibration and extraction. SPME extracts were presented in balanced order and labelled with numbers from 1 to 5 . Assessors were firstly asked to read the list of odour descriptors, then to smell the reference sample $(3.75 \mathrm{~mL})$ contained in an amber bottle $(30 \mathrm{~mL})$. Subsequently, they evaluated the different SPME extracts using $\mathrm{D}-\mathrm{GC}-\mathrm{O}$ in one session, rating the similarity to the reference using a $10-\mathrm{cm}$ line scale, ranging from 0 (far from reference) to 10 (close to reference). At the end of the evaluation, the panellists were asked to describe the differences between the odour of the SPME extract and that of the reference. Between sample evaluations, panellists had to smell the reference again. Panellists individually rated samples in duplicate on two separate days.

The SPME extracts were evaluated by $\mathrm{D}-\mathrm{GC}-\mathrm{O}$, using a Hewlett-Packard 5890 gas 
connected the injection port to the sniffing port. The carrier gas was helium with a flow rate of $10 \mathrm{~mL} / \mathrm{min}$. The SPME extracts were injected in splitless mode (injector temperature at $240{ }^{\circ} \mathrm{C}$ ) and the oven temperature was kept at $50{ }^{\circ} \mathrm{C}$. Since the short capillary contained no stationary phase, there was no chromatographic separation of compounds in the SPME extract and the extracts were assessed as "global" odour (Rega et al., 2003).

\subsection{Gas chromatography-mass spectrometry $(G C-M S)$}

Sample aliquots $(2.5 \mathrm{~mL})$ were added to 20 -mL screw-cap glass vials and headspace SPME was performed using an Agilent GC Sampler 120 PAL autosampler (Agilent Technologies, Santa Clara, CA). A Stableflex 50/30 $\mu \mathrm{m}$ DVB/CAR/PDMS SPME fibre was used for extraction (Supelco, Bellefonte, PA) and samples were agitated during equilibration and extraction. Analyses were conducted using a 7890A gas chromatography system (Agilent Technologies) attached to a 5975C inert MSD triple-axis detector (Agilent Technologies). The injection port was kept at $240{ }^{\circ} \mathrm{C}$ and the fibre was desorbed in the injection port in pulsed splitless mode for $45 \mathrm{~s}$, with a pressure pulse of 25 psi. Helium was used as carrier gas and flow through the column was constant at $1.2 \mathrm{~mL} / \mathrm{min}\left(8.5 \mathrm{psi}\right.$ at $\left.30^{\circ} \mathrm{C}\right)$. A ZB-5MSi $(30$ m, $0.25 \mathrm{~mm}$ i.d., $1 \mu \mathrm{m}$ film thickness; Phenomenex, Torrance, CA) capillary column was used for volatile compound separation. The initial oven temperature was held at $30{ }^{\circ} \mathrm{C}$ for 4 min. It was then raised at $4{ }^{\circ} \mathrm{C} / \mathrm{min}$ to $200{ }^{\circ} \mathrm{C}$, and finally at $8{ }^{\circ} \mathrm{C} / \mathrm{min}$ to $300{ }^{\circ} \mathrm{C}$, where the temperature remained constant for $1 \mathrm{~min}$.

The mass spectrometer operated in electron impact mode with an electron energy of $70 \mathrm{eV}$ and scanned from $\mathrm{m} / \mathrm{z}, 29$ to $\mathrm{m} / \mathrm{z}, 400$. The interface was at $280{ }^{\circ} \mathrm{C}$, the ion source at $230{ }^{\circ} \mathrm{C}$ and the quadrupole at $150{ }^{\circ} \mathrm{C}$. Peaks were identified by comparing retention times and mass spectra with those of reference compounds. The GC peak area was measured for each compound, in order to determine the release of volatiles from the sample, and all data were obtained in triplicate. 


\subsection{Statistical analysis}

The QDA results were statistically analysed by two-way analysis of variance (ANOVA) with sample and assessors fitted as fixed and random effects, respectively, and main effects tested against the assessor by sample interaction. Tukey's post hoc test was performed to identify significant differences between sample pairs $(p<0.05)$ (SENPAQ software; Qi Statistics, Ruscombe, UK). The GC peak areas of the flavour compounds recovered by GCMS were statistically analysed by one-way ANOVA and Tukey's post hoc test was applied to determine differences between samples. Principal component analysis, using the mean volatile data as the variables and with the mean sensory ratings (that were significantly different between samples) regressed onto the space as supplementary variables, was carried out using XLSTAT software Version 2014.6.01 (Addinsoft, Paris, France).

\section{Results and Discussion}

\subsection{Sensory analysis}

Figures 1 and 2 show the mean intensity scores for the sensory attributes, when samples were assessed orthonasally and retronasally, respectively. When analysed retronasally, 9 out of the 16 described attributes (listed in Supplementary Table S1) differed significantly between samples. However, when assessed orthonasally, only one attribute, "overripe orange", was found to vary significantly with sugar concentration. As sugar was not replaced with sweeteners in this study, then the taste attributes rated were expected to significantly differ between samples when assessed retronasally. Indeed, as can be seen in Figure 2, sweet taste increased significantly with sugar content and the sample with the least sugar $\left(5.2^{\circ}\right.$ Brix $)$ had a significantly higher bitter taste, as might be expected because sweetness suppresses bitterness (Green, Lim, Osterhoff, Blacher, \& Nachtigal, 2010). As expected, "syrupy" mouthfeel significantly increased with sugar content, especially at 11.2 and $14.2{ }^{\circ}$ Brix. In 
addition, the tactile sensation "astringency" (drying in nasal cavity) and "mouth-drying" were found to significantly decrease with sugar content, as supported by previous literature (Lyman \& Green, 1990). Considering the ratings of the retronasal flavour attributes "fresh ripe orange", "cooked orange", "artificial orange", "citrus/non-orange” and "overall orange strength", these were found to vary significantly with the sucrose content, as shown in Figure 2. Apart from "citrus/non-orange", the perceived intensities of the remaining attributes showed an increase with increasing sugar content. The effect of sugar concentration on the "overall orange strength" perception was the most pronounced. This overall odour intensity significantly increased as sugar content increased. Likewise, the intensity of the attributes "cooked orange" and "artificial orange" increased, from the low-sugar samples to the highsugar samples. However, this effect was not consistent in the case of "fresh ripe orange", where the scores increased gradually from samples $5.2{ }^{\circ}$ Brix until $11.2{ }^{\circ}$ Brix, but a significant reduction occurred in the score of the $14.2{ }^{\circ}$ Brix sample. As this evaluation was retronasal, significant differences in flavour perception with sugar content may be attributed to either differences in flavour release or to cross-modal taste enhancement. aroma compounds released in the vapour phase of a model system (Rega et al., 2004). The perceived intensity of an aroma is a function of the initial concentration in the model system as well as the physical parameters that determine molecular transfer into the headspace. Subsequently, any perceived alterations detected by the trained panel between samples could be explained by differences in release of the various volatiles when sugar concentration is modified. Therefore, it is hypothesised that as sucrose concentration increased, the perceived intensity of these attributes may have increased, due to a salting-out effect. As literature suggests, the "fresh" quality could be associated with terpenic compounds, whereas hexanal and decanal could be responsible for the "fruity/fresh" intensity. Finally, the "artificial" and 
"overall" intensity could be related to ethyl butanoate, which is characterised by a strong "sweet orange" quality. Linalool has been found to impart "cooked" quality (Rega et al., 2004). However, from the retronasal evaluation we cannot rule out cross-modal enhancement of the "cooked orange", "artificial orange", "citrus/non-orange" notes as well as "overall orange strength" by the sweet taste, as sweetness is known to enhance the perception of sweet-congruent flavours (Lim, Fujimaru, \& Linscott, 2014).

When the assessment was orthonasal any differences with sucrose content should be due to flavour release as they cannot be due to perceptual cross-modal effects. Therefore, we propose that the trend of "overripe orange "orthonasal aroma to increase with sugar content (Figure 1), which was significant between the 8.2 and $14.2{ }^{\circ}$ Brix samples, is due to a saltingout effect.

\subsection{Aroma quality analysis by $H S-S P M E / D-G C-O$}

Five SPME extraction procedures were examined, varying three sampling conditions (Table 1), with the sensory panel comparing each extract to the complete reference juice at 11.2 ${ }^{\circ}$ Brix. Generally, a short time of fibre exposure was preferred, since many studies suggested that a shorter time of sampling shows better sensitivity and less likelihood of fibre overloading from compounds with high affinity to the coated material of the fibre (Rega et al., 2003; Roberts et al., 2000). The mean similarity ratings (scored out of 10) obtained from the trained sensory panel for each of the extraction conditions varied from 4.8 to 6.3 , although these differences were not significant $(p=0.068)$. Overall, this showed that the odour of the SPME extracts did not perfectly match that of the reference sample. Although the differences were not significant, it is interesting to note that the aroma of the extract with the highest fibre sampling time $(5 \mathrm{~min})$ was rated to be the least like the reference sample, which agreed with previous studies (Rega et al., 2003; Roberts et al., 2000). The equilibration temperature of $40{ }^{\circ} \mathrm{C}$ tended to give greater similarity than $30{ }^{\circ} \mathrm{C}$, while the combination of 
$40{ }^{\circ} \mathrm{C}$ for 30 min with agitation has been previously reported as one of the most suitable sampling conditions for the headspace analysis of orange flavour compounds (Jia et al., 1998). The experimental conditions that provided the most representative extract $\left(40{ }^{\circ} \mathrm{C}\right.$ equilibration for 30 min followed by 1 min fibre exposure) were used for all subsequent HSSPME/GC-MS analyses.

\subsection{Gas chromatography-mass spectrometry (GC-MS)}

The experimental data of flavour release from the orange juice model system at varying sucrose concentrations are presented in Figure 3. Although limonene was absent from the flavouring, it was present as the compound with the largest peak area in the GC-MS trace. The limonene is a component of the orange pulp, which was not fully removed by the deodorisation process. Because of its importance in citrus, it was decided to examine how this compound varied as a result of sucrose reduction.

Overall, the results show a significant decrease in the concentration of hexanal, $\alpha$-pinene, $\beta$-myrcene, limonene, linalool and decanal by decreasing sugar content $(p<0.05)$. These findings might be attributed to the salting-out of flavour volatiles into the headspace above the samples when sucrose interacts with water, resulting in increased concentration of the flavour compounds in the remaining "unbound water" (Friel, Linforth, \& Taylor, 2000; Hansson et al., 2001; Rabe et al., 2003).

The decreasing sugar did not lead to a consistent decrease in the release of ethyl butanoate and although the release of hexanal was significantly different between samples, the extent of difference was small and the relationship between sugar concentration and hexanal release was not consistent. There was an observable trend that the release of (Z)-3-hexen-1-ol slightly varied with sugar content (at a significance value, $p<0.05$ ), whereas linalool release significantly decreased with decreasing sugar concentration. The release of these flavour compounds has been reported to increase at elevated sucrose levels in soft drink model 
systems (Hansson et al., 2001; Rabe et al., 2003). It is an indication that changes in the sugar levels used in commercial soft drinks slightly modify the amount of "free water", which subsequently has a minor effect on salting-out of some aroma compounds.

Moreover, one robust finding to have emerged from the current HS-SPME analysis is the clear and significant pattern observed in the concentrations of $\alpha$-pinene, $\beta$-myrcene, limonene and decanal, aroma compounds with relatively high molecular weights and relatively low polarities. Release of these volatile compounds showed a significant increase from $5.2^{\circ}$ Brix to $14.2^{\circ} \mathrm{Brix}$ while release at the intermediate sucrose levels of $8.2^{\circ} \mathrm{Brix}, 9.7^{\circ} \mathrm{Brix}$ and 11.2 ${ }^{\circ}$ Brix did not statistically differ. Regardless of the aforementioned salting-out effect, the up to 4-fold increased release of these compounds could be additionally explained by the strong polar environment of the model system, the hydrophobic nature of these flavour compounds and the low pulp content which such hydrocarbons are more associated with; a positive correlation between reduction of pulp content and decreasing release of hydrophobic compounds has been found (Berlinet et al., 2007). A previous study reported that limonene did not show any significant changes in its release into the headspace above a soft drink model system across different sugar concentrations ranging from 20 to $60 \% \mathrm{w} / \mathrm{v}$, due to the non-polar character of this compound (Hansson et al., 2001).

Low variation in the quantification of flavour compounds between replicates was observed using the SPME/GC-MS conditions optimised in this study. This indicates both that equilibrium had been reached in sampling and that the ratio between the added volume of the orange juice and the total volume of the vial (1:8) was optimal. Likewise, the sugar levels used in the current model system are low, resulting in limited complexity of the hydration processes and low variability of the experimental data, as has been suggested in a previous study (Rabe et al., 2003).

\subsection{Comparison of sensory and analytical data}



compounds determined in the HS-SPME extracts of the samples, with the sensory data for the same samples fitted onto the PCA plot as supplementary variables (Figure 4), assuming that the sensory perception of the orange juice soft drinks was affected by their volatile flavour profile. Specifically, one orthonasal $(\mathrm{O})$ and five retronasal attributes $(\mathrm{R})$ were used for this analysis; the attributes that differed significantly between samples. Similarly, among the volatile compounds of the model flavour mixture, only ethyl butanoate was excluded from the principal component analysis, since it did not vary with sugar concentration. The first two principal components accounted for $94 \%$ of the variance in the data; principal component 1 (PC1) explained $73.5 \%$ of the variance, discriminating samples in terms of "sugar content", and principal component 2 (PC2) explained a further $20.5 \%$ variance. PC1 placed the $5.2{ }^{\circ}$ Brix soft drink on the left-hand side and the $14.2^{\circ}$ Brix on the right-hand side. headspace of juices and soft drinks are directly associated with the orthonasal perception of them. Therefore, the perceived differences in the orthonasal attribute "overripe orange" detected by the sensory panel with increasing sugar content could be partly attributed to changes found in the volatiles released into the headspace. Specifically, the correlation matrix showed that the orthonasal "overripe orange" attribute was strongly correlated with all the flavour volatiles apart from the aldehyde hexanal (no correlation was found with this volatile molecule). This indicates that the release of these flavour compounds, as a total, gave a major sensorial impact on the perceived intensity of the sensory orthonasal quality of "overripe orange"; as reflected by PC1 (Figure 4). Finally, this finding confirms our hypothesis that the detected differences in the orthonasal perception by the sensory panel could be attributed to the "salting-out" of the volatiles into the headspace above samples. 
The retronasal perception is more complex and could be affected by many factors (not only the physical parameters of the soft drink) and interactions between different sensory modalities. Therefore, differences in the release of the flavour volatiles into the headspace cannot directly correspond to differences detected during the retronasal evaluation. The volatile compounds (Z)-3-hexen-1-ol, $\alpha$-pinene, $\beta$-myrcene, limonene, linalool and decanal were very well correlated with all the sensory variables apart from the retronasal "fresh ripe orange". Under closer inspection, this finding has a two-fold importance for the current study.

On the one hand, the flavour volatiles appeared to impart a substantial contribution to the perceived intensity of these sensory attributes as a group and not as individual compounds; on the other hand, the retronasal attribute "fresh ripe orange" showed weak correlations with all volatiles, indicating that differences in the release of these volatiles did not reflect changes in the intensity of this sensory attribute. In contrast, the "citrus/non-orange" attribute was found to be negatively associated with all other dependent variables. Moreover, only the sample at $5.2{ }^{\circ}$ Brix was positively correlated with the retronasal "citrus/non-orange" attribute. This finding indicates that the retronasal quality of "citrus/non-orange" could be a result of low release concentrations of the flavour volatiles in the soft drink containing $5.2^{\circ}$ Brix sugar content and not due to a single flavour compound. Also, the increased intensity of "citrus/non-orange" found in $5.2^{\circ}$ Brix sample could be attributed to the increased perceived bitterness, as a similar pattern in ratings was observed for this odour and taste descriptor. The sample with $14.2^{\circ}$ Brix sugar content was found to be highly correlated with all the volatile and sensory data used in the principal component analysis. In fact, the aforementioned extreme sensory findings between samples with 5.2 and $14.2^{\circ}$ Brix sugar content suggest that, apart from the observed physical effects (salting-out of volatiles), the perceived differences in the retronasal evaluation might be attributed to bitterness and sweetness enhancement, 
respectively (cognitive cross-modal enhancement) (Hornung \& Enns, 1986; Stampanoni, 1993).

In the case of hexanal, negligible correlations with all the remaining variables were found. This finding suggests that hexanal had very little, if any, contribution to the flavour perception of the samples. This is not supported by the literature, which suggests that fresh flavour notes are imparted by aldehydes (Rega et al., 2004). However, it could be explained by the low concentration of hexanal in the flavour mixture and subsequently in its lower release compared to the other volatiles in the current model system. This is also supported by the very low intensity rating of green/grassy odour given by the sensory panel. At $5.2^{\circ}$ Brix the relatively high headspace concentrations of linalool, ethyl acetate, (Z)-3-hexen-1-ol and hexanal, relative to those of decanal and the monoterpenes, may also be associated with the increase in the citrus/non-orange attribute. For example, at $5.2{ }^{\circ}$ Brix, the ratio between the headspace peak areas for $\beta$-myrcene and ethyl butanoate is about 1.5 , while at $14.2^{\circ}$ Brix, the ratio is about 6 . This change could affect the balance of the flavouring at reduced sugar content, resulting in the observed sensory differences.

Although the viscosities of the model orange soft drinks were not measured in this work, other workers (Hewson, Hollowood, Chandra, \& Hort, 2008), who examined sugar levels close to the range used in this study, suggested that the small viscosity differences they observed (0.4 mPa s) may not affect assessor perception. Kappes, Schmidt, and Lee (2006) plotted sucrose solution concentration against viscosity. Their results suggested that the difference in viscosity between the $5.2{ }^{\circ}$ Brix and $14.2{ }^{\circ}$ Brix model solutions was approximately $0.5 \mathrm{mPa}$ s. These authors suggested that a viscosity difference of $0.527 \mathrm{mPa} \mathrm{s}$ could cause a perceived difference in mouthfeel. However, they were focusing on the effect of sweetener removal on mouthfeel and they were comparing diet and regular cola carbonated beverages, with an added sweetness suppressant. Based on these observations, it 
seems unlikely that viscosity differences in the five orange juice model solutions would affect flavour release.

\section{Conclusions}

The results obtained from sensory and flavour release analysis concluded that a "saltingout" effect of volatiles into the headspace could be observed within sugar levels normally used in commercial soft drinks. It was observed that the ratings of some orthonasal and retronasal attributes significantly $(p<0.05)$ varied by sugar level reduction.

The D-GC-O method, which was conducted, in order to assess the odour quality of the

SPME extracts by applying different sampling conditions, proved to be a valuable research tool, capable of giving to the researcher confidence about the quality and the representativeness of an SPME extract.

The HS-SPME/GC-MS analysis successfully determined an association between the release behaviour of volatile compounds (selected because of their odour quality) and their importance in orange juice flavour. Principal component analysis was able to explain about $95 \%$ of the data variability and strongly correlated the perceived intensity of the orthonasal attribute "overripe orange" with the release of the flavour compounds, as a total, supporting the "salting out" hypothesis. However, it remains questionable whether the perceived differences in the retronasal evaluation might be attributed to sweetness enhancement rather than flavour release.

\section{Acknowledgements}

The authors would like to gratefully acknowledge the financial support by the Seventh 434 Framework programme (FP7) of the European Union under the Marie Curie Initial Training 435 Network 'HST FoodTrain' (Grant agreement 264470). 


\section{References}

438

439

440

441

442

443

444

445

446

447

448

449

450

451

452

453

454

455

456

457

Bazemore, R., Goodner, K., \& Rouseff, R. (1999). Volatiles from unpasteurized and excessively heated orange juice analyzed with solid phase microextraction and GColfactometry. Journal of Food Science, 64 (5), 800-803.

Berlinet, C., Guichard, E., Fournier, N., \& Ducruet, V. (2007). Effect of pulp reduction and pasteurization on the release of aroma compounds in industrial orange juice. Journal of Food Science, 72 (8), S535-S543.

Friel, E. N., Linforth, R. S. T., \& Taylor, A. J. (2000). An empirical model to predict the headspace concentration of volatile compounds above solutions containing sucrose. Food Chemistry, 71(3), 309-317.

González-Mas, M. C., Rambla, J. L., Alamar, M. C., Gutiérrez, A., \& Granell, A. (2011). Comparative analysis of the volatile fraction of fruit juice from different citrus species. PLoS ONE, 6 (7), e22016.

Green, B. G., Lim, J., Osterhoff, F., Blacher, K., \& Nachtigal, D. (2010). Taste mixture interactions: Suppression, additivity, and the predominance of sweetness. Physiology \& Behavior, 101 (5), 731-737.

Hansson, A., Andersson, J., \& Leufven, A. (2001). The effect of sugars and pectin on flavour release from a soft drink-related model system. Food Chemistry, 72 (3), 363-368.

Hewson, L., Hollowood, T., Chandra, S., \& Hort, J. (2008). Taste-aroma interactions in a citrus flavoured model beverage system: Similarities and differences between acid and sugar type. Food Quality and Preference, 19, 323-334. 
Hornung, D. E., \& Enns, M. P. (1986). The contributions of smell and taste to overall 459 intensity: A model. Perception and Psychophysics, 39, 385-391.

460

Jia, M., Zhang, Q. H., \& Min, D. B. (1998). Optimization of solid-phase microextraction 461 analysis for headspace flavor compounds of orange juice. Journal of Agricultural and Food 462 Chemistry, 46 (7), 2744-2747.

Kappes, S. M., Schmidt, S. J., \& Lee, S. Y. (2006). Mouthfeel detection threshold and 464 instrumental viscosity of sucrose and high fructose corn syrup solutions. Journal of Food Science, 71, S597-S602.

466

Lim, J., Fujimaru, T., \& Linscott, T. D. (2014). The role of congruency in taste-odor 467 interactions. Food Quality and Preference, 34, 5-13.

Lyman, B. J., \& Green, B. G. (1990). Oral astringency - Effects of repeated exposure and 469 interactions with sweeteners. Chemical Senses, 15 (2), 151-164.

470 Moshonas, M. G., \& Shaw, P. E. (1994). Quantitative determination of 46 volatile 471 constituents in fresh, unpasteurized orange juices using dynamic headspace gas chromatography. Journal of Agricultural and Food Chemistry, 42 (7), 1525-1528.

473 Nahon, D. F., Roozen, J. P., \& de Graaf, C. (1998). Sensory evaluation of mixtures of sodium 474 cyclamate, sucrose, and an orange aroma. Journal of Agricultural and Food Chemistry, 46 475 (9), 3426-3430.

476 Perez-Cacho, P. R., \& Rouseff, R. L. (2008). Fresh squeezed orange juice odor: a review. 477 Critical Reviews in Food Science and Nutrition, 48 (7), 681-695. 
478 Plotto, A., Margaría, C. A., Goodner, K. L., \& Baldwin, E. A. (2008). Odour and flavour

479

480

481

482

483

484

485

486

487

488

489

490

491

492

493

494

495

496

497

498

thresholds for key aroma components in an orange juice matrix: esters and miscellaneous compounds. Flavour and Fragrance Journal, 23 (6), 398-406.

Plotto, A., Margaría, C. A., Goodner, K. L., Goodrich, R., \& Baldwin, E. A. (2004). Odour and flavour thresholds for key aroma components in an orange juice matrix: terpenes and aldehydes. Flavour and Fragrance Journal, 19 (6), 491-498.

Rabe, S., Krings, U., \& Berger, R. G. (2003). Dynamic flavor release from sucrose solutions. Journal of Agricultural and Food Chemistry, 51 (17), 5058-5066.

Rega, B., Fournier, N., \& Guichard, E. (2003). Solid phase microextraction (SPME) of orange juice flavor: odor representativeness by direct gas chromatography olfactometry (DGC-O). Journal of Agricultural and Food Chemistry, 51 (24), 7092-7099.

Rega, B., Fournier, N., Nicklaus, S., \& Guichard, E. (2004). Role of pulp in flavor release and sensory perception in orange juice. Journal of Agricultural and Food Chemistry, 52 (13), $4204-4212$.

Roberts, D. D., Pollien, P., \& Milo, C. (2000). Solid-phase microextraction method development for headspace analysis of volatile flavor compounds. Journal of Agricultural and Food Chemistry, 48 (6), 2430-2437.

Stampanoni, C. R. (1993). Influence of acid and sugar content on sweetness, sourness and the flavour profile of beverages and sherbets. Food Quality and Preference, 4(3), 169-176.

Yang, X., \& Peppard, T. (1994). Solid-phase microextraction for flavor analysis. Journal of Agricultural and Food Chemistry, 42 (9), 1925-1930. 
499 Zhang, Z., \& Pawliszyn, J. (1993). Headspace solid-phase microextraction. Analytical 500 Chemistry, 65 (14), 1843-1852.

501 
503 Fig. 1. Orthonasal evaluation of samples: mean perceived intensity (0-100) of all sensory 504 attributes (different letters above the bars represent significant differences at $p<0.05$ from 505 Tukey's HSD test)

506 Fig. 2. Retronasal evaluation of samples: mean perceived intensity (0-100) of all sensory 507 attributes (flavour, taste and mouthfeel) (different letters above the bars represent significant 508 differences at $p<0.05$ from Tukey's HSD test)

509 Fig.3.Effect of sugar concentration on relative amounts of aroma compounds in the 510 headspace SPME extract of a model orange juice soft drink. Effect significant at:* $p<0.05$; $511 * * p<0.01 ; * * * p<0.001$; ns: not significant (error bars indicate standard deviation between 512 replicates $(n=3))$.

513 Fig. 4. Principal component analysis biplot where the volatile compound data (ם) that were 514 significantly different between samples $(\diamond)$ formed the multidimensional space and the 515 sensory attributes $(\checkmark)$ were regressed onto the space as supplementary variables; orthonasal 516 and retronasal evaluations have "O" and "R" letters, respectively. 
519 Examined experimental conditions of SPME extractions using a Stableflex 50/30 $\mu \mathrm{m}$

520 DVB/CAR/PDMS fibre

\begin{tabular}{ccc}
\hline $\begin{array}{c}\text { equilibrium } \\
\text { temperature } \\
\left({ }^{\circ} \mathbf{C}\right)\end{array}$ & $\begin{array}{c}\text { equilibrium } \\
\text { time (min) }\end{array}$ & $\begin{array}{c}\text { fibre } \\
\text { exposure } \\
\text { time } \\
(\mathbf{m i n})\end{array}$ \\
\hline 30 & 30 & 1 \\
\hline 30 & 30 & 5 \\
\hline 40 & 15 & 1 \\
\hline 40 & 30 & 0.5 \\
\hline 40 & 30 & 1 \\
\hline
\end{tabular}

521 
Figure 1:

524
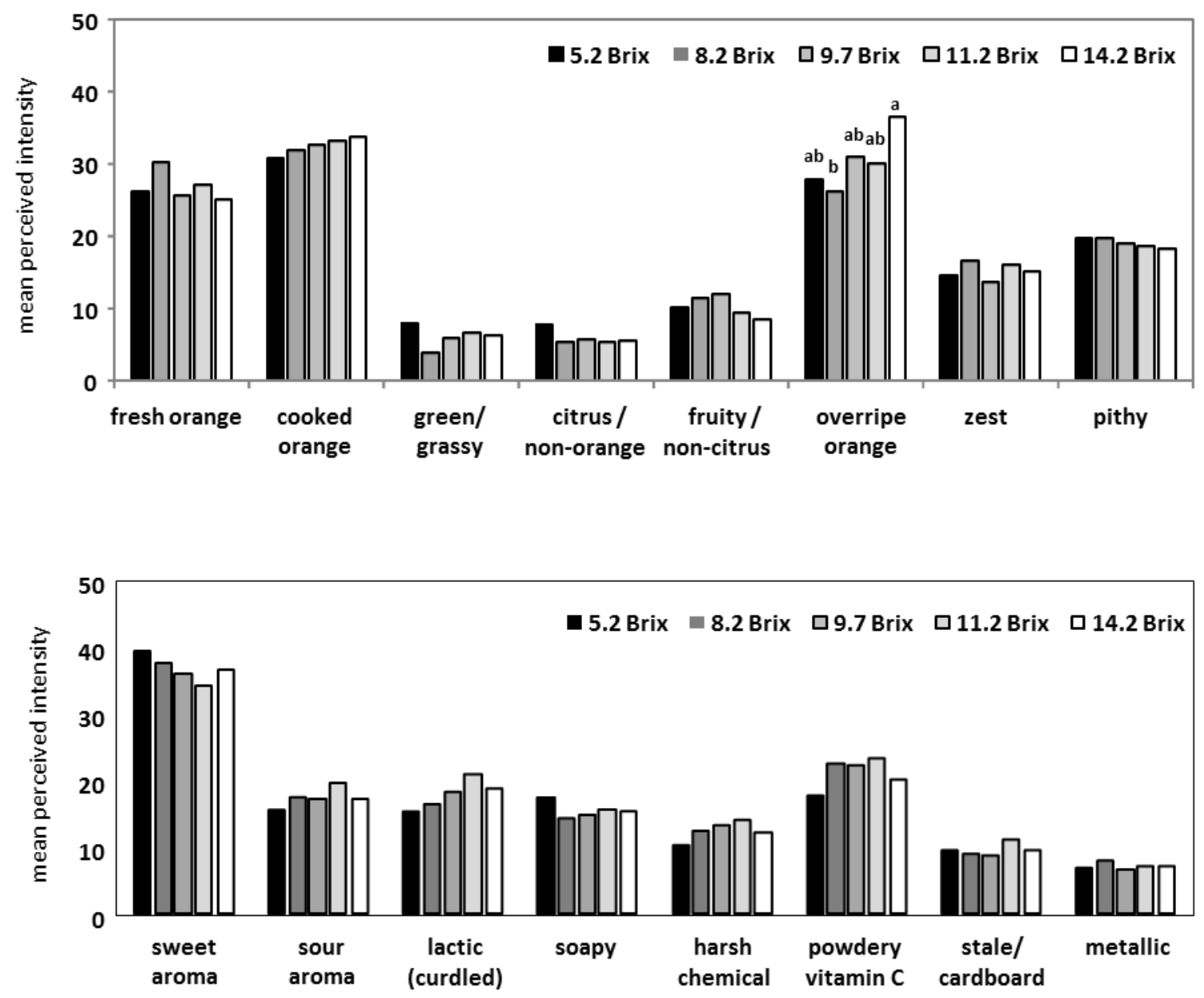
Figure 2:

527
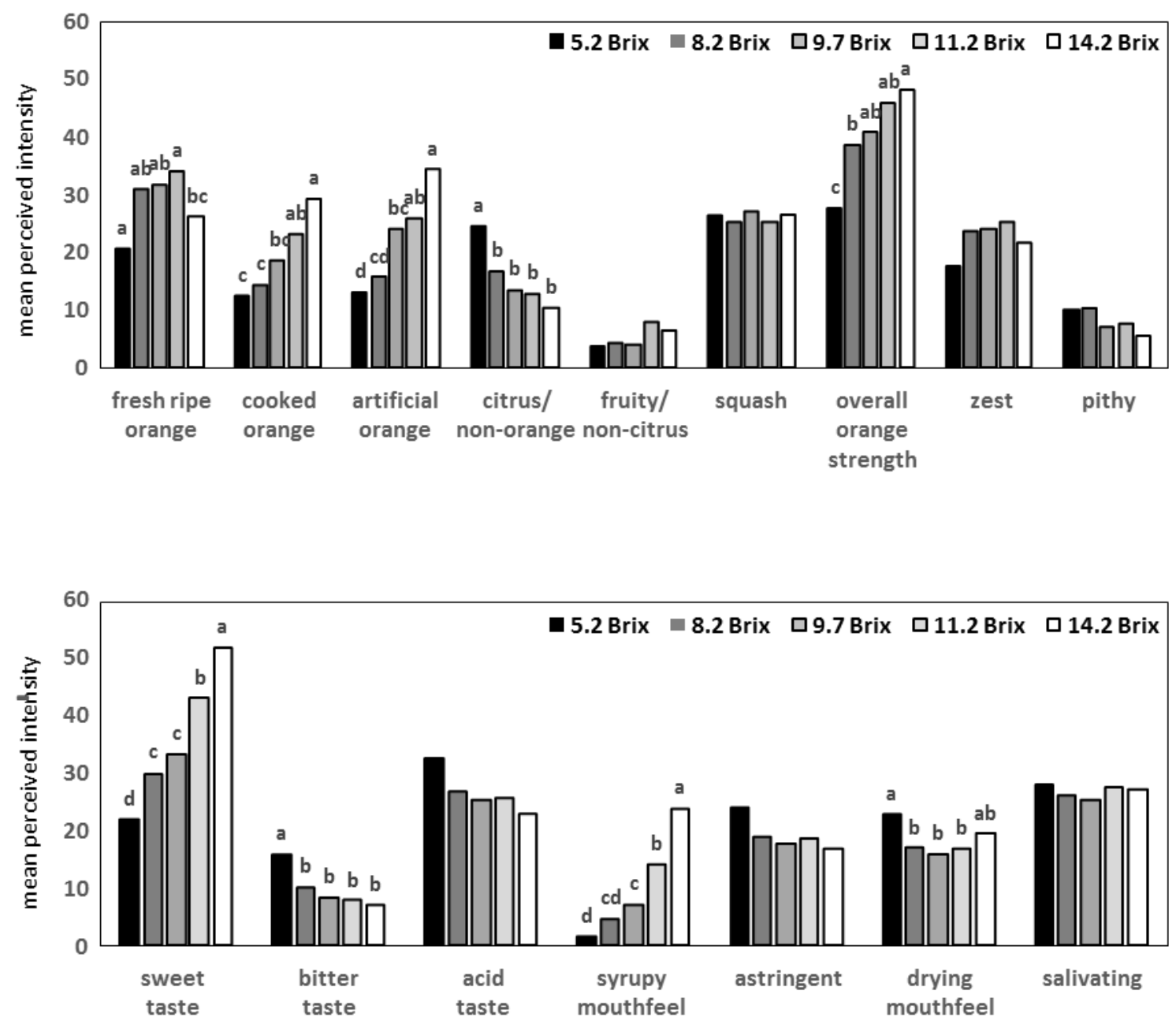

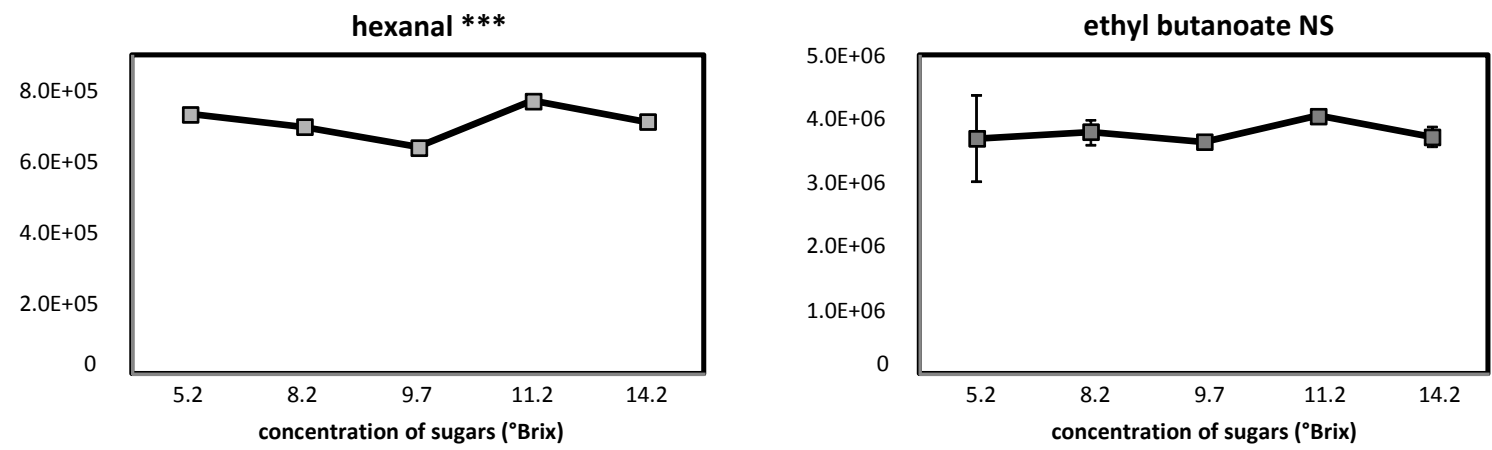

(Z)-3-hexen-1-ol *
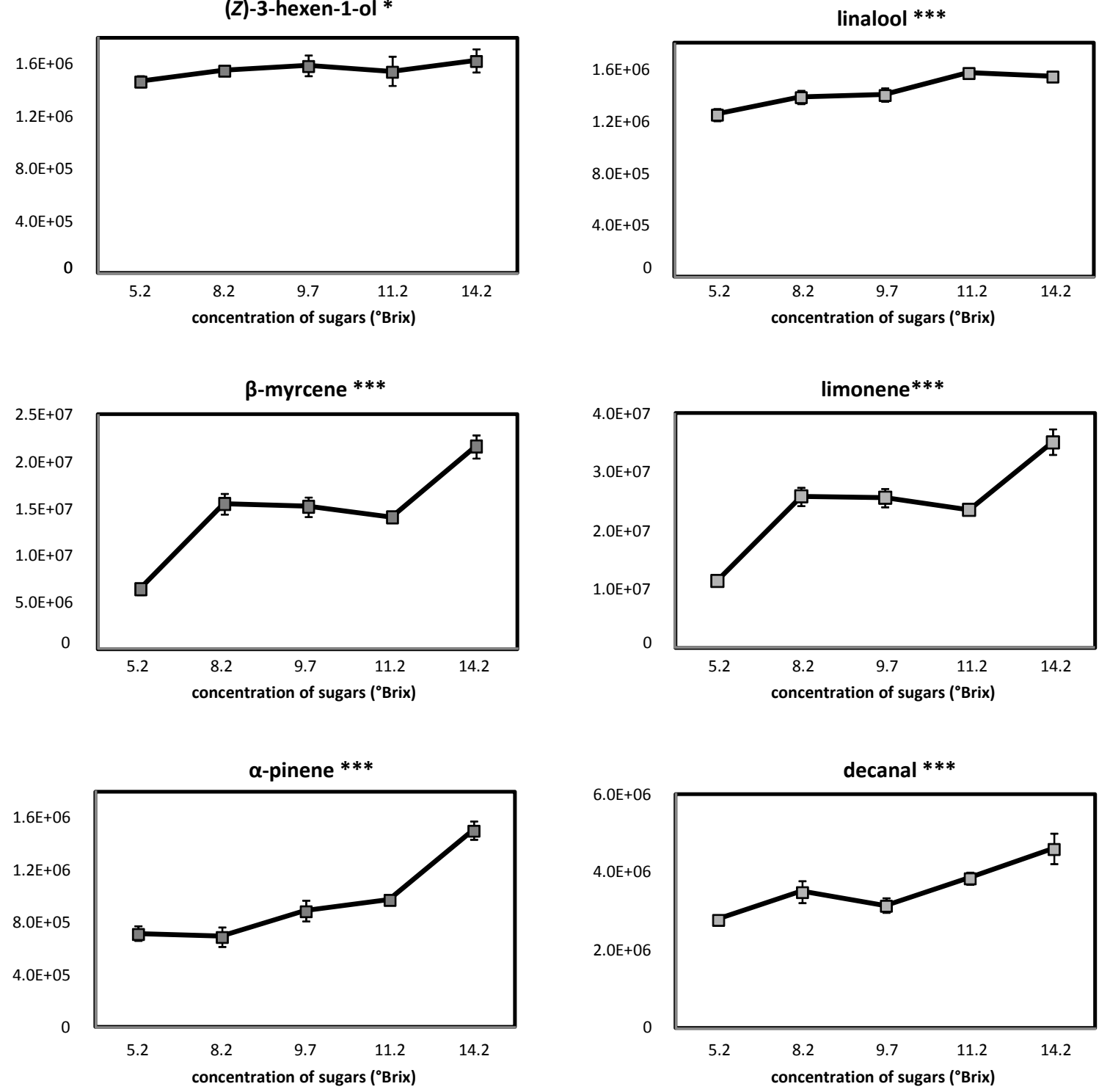
533 Figure 4:

534

Biplot (axes F1 and F2: 94\%)

535

536

537

538

539

540

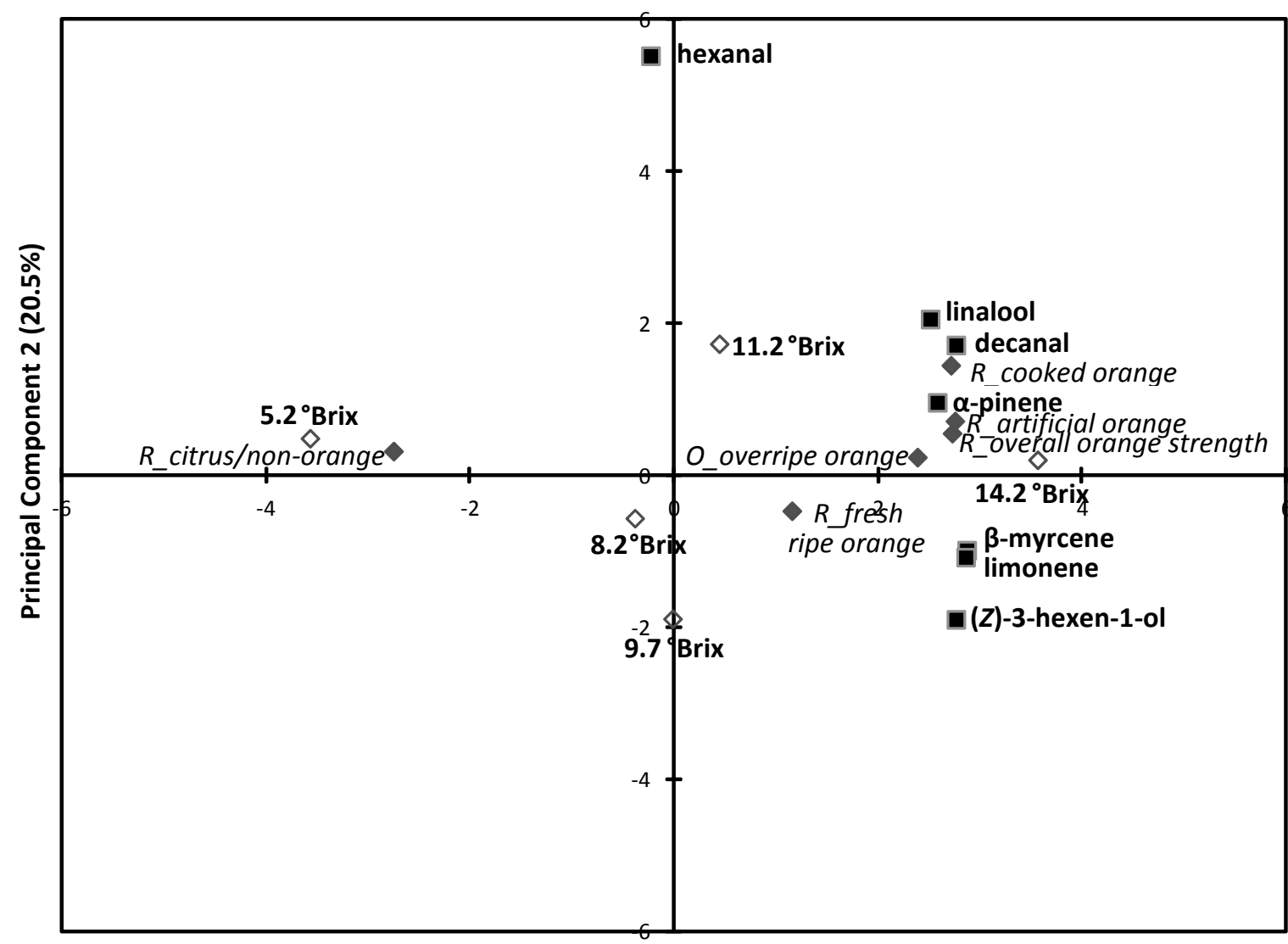

543

Principal Component 1 (73.5\%) 
